\title{
Preparation of $\gamma-\mathrm{Fe}_{2} \mathrm{O}_{3} / \mathrm{ZnFe}_{2} \mathrm{O}_{4}$ nanoparticles by enhancement of surface modification with $\mathrm{NaOH}$
}

\author{
Longlong Chen ${ }^{1}$, Jian Li ${ }^{1 *}$, Yueqiang Lin ${ }^{1}$, Xiaodong Liu ${ }^{1}$, Junming $\mathrm{Li}^{1}$, Xiaomin Gong ${ }^{1}$ and Decai Li ${ }^{2}$
}

\begin{abstract}
Background: During liquid-phase synthesis of $\mathrm{y}^{-} \mathrm{Fe}_{2} \mathrm{O}_{3}$ nanoparticles by chemically induced transition in $\mathrm{FeCl}_{2}$ solution, enhancement of surface modification by adding $\mathrm{ZnCl}_{2}$ was attempted by using $\mathrm{NaOH}$. By using transmission electron microscopy, X-ray diffraction, X-ray photoelectron spectroscopy, energy-dispersive X-ray spectrometry, and vibrating sample magnetometry, the dependence of the synthesis on the amount of additional $\mathrm{NaOH}$ was studied.

Results: The experimental results show that the surface of the $\mathrm{\gamma}^{-} \mathrm{Fe}_{2} \mathrm{O}_{3}$ nanoparticles could be modified by adding $\mathrm{ZnCl} 2$ to form composite nanoparticles with $\gamma-\mathrm{Fe}_{2} \mathrm{O}_{3} / \mathrm{ZnFe}_{2} \mathrm{O}_{4}$ ferrite core coated with $\mathrm{Zn}(\mathrm{OH})_{2}$ and adsorbed $\mathrm{FeCl}_{3}$, and that modification could be enhanced by adding $\mathrm{NaOH}$.

Conclusions: In the experimental conditions, when the concentration of additional $\mathrm{NaOH}$ was below $0.70 \mathrm{M}$, the amounts of $\mathrm{ZnFe}_{2} \mathrm{O}_{4}$ and $\mathrm{Zn}(\mathrm{OH})_{2}$ phases increased slightly and that of adsorbed $\mathrm{FeCl}_{3}$ was unchanged. When the concentration of $\mathrm{NaOH}$ exceeded $0.70 \mathrm{M}$, the amount of $\mathrm{FeCl}_{3}, \mathrm{ZnFe}_{2} \mathrm{O}_{4}$, and $\mathrm{Zn}(\mathrm{OH})_{2}$ increased.
\end{abstract}

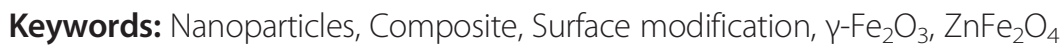

\section{Introduction}

Nanoparticles are typically defined as solids that are less than $100 \mathrm{~nm}$ in all three dimensions. Many physical phenomena in both organic and inorganic materials have natural length scales between 1 and $100 \mathrm{~nm}\left(10^{2}\right.$ to $10^{7}$ atoms) [1,2]. A nanocomposite is a material composed of two or more phases with at least one phase with nanometer dimensions. Due to combination of different physical or chemical properties, composite nanoparticles may lead to completely novel materials [3]. For example, the type and geometric arrangement of surface coating on a magnetic core determine the overall size of a nanocomposite colloid and play a significant role in its biological fate in biomedical applications [4].

Magnetic nanoparticles are an important class of functional materials that have attracted increasing interest in terms of their science and their technological applications [5]. Studies on ferromagnetic (FM)-antiferromagnetic (AFM) exchange interactions in systems of fine composite particle have led to interesting applications in improving the performance of permanent magnetic materials or in

\footnotetext{
* Correspondence: aizhong@swu.edu.cn

'School of Physical Science \& Technology, Southwest University, Chongqing 400715, People's Republic of China

Full list of author information is available at the end of the article
}

exceeding the superparamagnetic limit in magnetic recording media [6]. Studies on magnetic nanoparticles have focused on the development of novel technologies for their synthesis. Liquid-phase synthesis is still one of the most commonly used methods to obtain inorganic nanoparticles [7]. Many studies have shown that surface modification, which provides additional functionality to nanoparticles, is easily accomplished after or during synthesis [1]. Recently, we proposed a new method to produce magnetic nanoparticles. This method involves chemically induced transition in which $\gamma-\mathrm{Fe}_{2} \mathrm{O}_{3}$-based nanoparticles are prepared by processing a precursor based on iron oxide hydroxide and/or metal hydroxide in $\mathrm{FeCl}_{2}$ solution [8-10]. In this method, $\gamma-\mathrm{Fe}_{2} \mathrm{O}_{3}$ nanoparticles can be prepared by using an amorphous coating of $\mathrm{FeOOH}$ and $\mathrm{Mg}(\mathrm{OH})_{2}$, as described in the following equation [10]:

$$
\begin{aligned}
2 \mathrm{FeOOH} & +\mathrm{Mg}(\mathrm{OH})_{2} \underset{\text { (heating) }}{\stackrel{\mathrm{FeCl}_{2} \text { solution }}{\gtrless}} \gamma-\mathrm{Fe}_{2} \mathrm{O}_{3} \downarrow \\
& +\mathrm{H}_{2} \mathrm{O}+\mathrm{Mg}^{2+}+2 \mathrm{OH}^{-}
\end{aligned}
$$

In another study, surface modification of the particles was undertaken during synthesis by adding $\mathrm{ZnCl}_{2}$ to the $\mathrm{FeCl}_{2}$ solution to prepare $\gamma-\mathrm{Fe}_{2} \mathrm{O}_{3} / \mathrm{ZnFe}_{2} \mathrm{O}_{4}$ composite nanoparticles [11]. Experimental results show that when the concentration of $\mathrm{ZnCl}_{2}$ in solution did not exceed 
$2 \mathrm{M}(50 \mathrm{~mL}), \gamma-\mathrm{Fe}_{2} \mathrm{O}_{3} / \mathrm{ZnFe}_{2} \mathrm{O}_{4}$ bioxide nanoparticles coated with $\mathrm{FeCl}_{3} \cdot 6 \mathrm{H}_{2} \mathrm{O}$ could be prepared. Generally, alkaline solution could assist the precipitation reaction. In the present work, we attempted to enhance the surface modification by adding $\mathrm{NaOH}$ to the processing solution. The morphology, crystal structure, surface and bulk chemical composition, and magnetization of the as-prepared products were characterized. The structure of the particles was proposed and the role of $\mathrm{NaOH}$ was revealed.

\section{Experimental \\ Preparation}

Preparation of the nanoparticles could be divided into two steps. First, the precursor based on amorphous FeOOH and $\mathrm{Mg}(\mathrm{OH})_{2}$ was synthesized by coprecipitation of $\mathrm{FeCl}_{3}$ and $\mathrm{Mg}\left(\mathrm{NO}_{3}\right)_{2}$, as described in detail elsewhere [10]. In the second step, the precursor was added to 400 $\mathrm{mL}$ of $0.25 \mathrm{M} \mathrm{FeCl}_{2}$ solution, and the resulting mixture was heated to boiling for $20 \mathrm{~min}$. Afterward, a mixture of $50 \mathrm{~mL}$ of $1 \mathrm{M} \mathrm{ZnCl}_{2}$ solution and $20 \mathrm{~mL} \mathrm{NaOH}$ solution at a specific concentration was added to the boiling $\mathrm{FeCl}_{2}$ solution, and the resulting mixture was boiled continuously for $10 \mathrm{~min}$. Subsequently, the mixture was allowed to cool to room temperature, and the as-prepared particles were allowed to settle. The $\mathrm{NaOH}$ concentrations used for the preparation were $0.35,0.70,1.40$, and $2.10 \mathrm{M}$, corresponding to the as-prepared samples (1), (2), (3), and (4), respectively. For comparison, modified particles were prepared without adding $\mathrm{NaOH}$ (sample (0)).

\section{Characterization}

The morphology of the particles in the samples was observed by transmission electron microscopy (TEM, Philips Tecnai 10), and their crystal structure was analyzed by X-ray diffraction (XRD, XD-2). The chemical species were measured using X-ray photoelectron spectroscopy (XPS, XSAM 800), and energy-dispersive X-ray spectroscopy (EDX, Genesis) equipped in scanning electron microscopy (SEM, Quanta-200). The magnetization was measured by using a vibrating sample magnetometer (VSM, HH-15).

\section{Results and analysis}

TEM images of the samples are shown in Figure 1. It can be seen that sample (0) consisted of nearly spherical nanoparticles. Statistical analysis showed that the size of the particles fit a log-normal distribution, with the median diameter $d_{g}$ about $9.78 \mathrm{~nm}$ and the standard deviation $\ln \sigma_{\mathrm{g}}=0.28$. Samples (1) - (4) images indicated that these samples consisted of irregular flake particles and nearly spherical particles, whose sizes are clearly larger than size of sample (0). This shows that $\mathrm{NaOH}$ can stimulate aggregation of the initial particles to grow into larger particles via oriented attachment [12].
XRD patterns (Figure 2) reveal that the samples contained mainly $\gamma-\mathrm{Fe}_{2} \mathrm{O}_{3}$ and traces of $\mathrm{ZnFe}_{2} \mathrm{O}_{4}$ and $\mathrm{Zn}(\mathrm{OH})_{2}$, but no $\mathrm{ZnCl}_{2}$.

XPS measurements show that $\mathrm{O}, \mathrm{Fe}, \mathrm{Zn}$, and $\mathrm{Cl}$ but no $\mathrm{Mg}$ and $\mathrm{Na}$ species were present in the samples, as illustrated in Figure 3. Therefore, the samples consisted of $\mathrm{Fe}_{2} \mathrm{O}_{3}, \mathrm{ZnFe}_{2} \mathrm{O}_{4}, \mathrm{Zn}(\mathrm{OH})_{2}$, and $\mathrm{FeCl}_{3}$. Binding energy data are listed in Table 1. As a comparison, the binding energy data of $\mathrm{ZnCl}_{2}$ [13] are listed also in Table 1 . Obviously, the data of measured deviate from data of $\mathrm{ZnCl}_{2}$. Quantitative analysis, whose relative error are less that $1 \%$, shows that relative to sample (0) this ratio of $\mathrm{Fe}$ to $\mathrm{Cl}$ keeps almost invariant for low $\mathrm{NaOH}$ concentrations (up to $0.70 \mathrm{M}$ ) - samples (1) and (2), but it increase with $\mathrm{NaOH}$ concentrations above that level - sample (3) and (4). Alternatively, to use the same criteria used for the ratio of $\mathrm{Fe}$ to $\mathrm{Zn}$ of samples, $(1) \approx(2)<(3)<(4)$. Complete data are listed in Table 2.

The results of EDX measurements of all samples confirm the same chemical species as those detected by XPS. Results of quantitative analysis, whose relative error are less in $2 \%$, are listed in Table 3. Evidently, the $\mathrm{Fe}: \mathrm{Cl}$ and $\mathrm{Fe}: \mathrm{Zn}$ ratios show the same trends for the samples as those observed with XPS.

Figure 4 shows the specific magnetization curves of the samples. All samples showed distinct FM behavior. Their specific saturation values $\sigma_{\mathrm{s}}$ were deduced by plotting $\sigma$ vs. $1 / H$ in the high-field region [14]. These values were found to be 52.29, 53.63, 58.29, 55.09, and $47.15 \mathrm{emu} / \mathrm{g}$ for samples (0), (1), (2), (3), and (4), respectively. Magnetization of samples (0) and (1) were nearly the same, that of sample (2) was the strongest, and the magnetization weakened gradually from samples (2) to sample (4).

\section{Discussion}

The experimental results and analysis above indicate that all of the samples were composed of $\gamma-\mathrm{Fe}_{2} \mathrm{O}_{3}$, $\mathrm{ZnFe}_{2} \mathrm{O}_{4}, \mathrm{Zn}(\mathrm{OH})_{2}$ and $\mathrm{FeCl}_{3}$, and no $\mathrm{ZnCl}_{2}$. The experimental results show that the ratios of $\mathrm{Fe}$ to $\mathrm{Cl}$ and Fe to $\mathrm{Zn}$ obtained by XPS were less than those obtained by EDX spectrometry, and the ratio of $\mathrm{Cl}$ to $\mathrm{Zn}$ obtained by XPS agree with that obtained by EDX spectrometry (see Tables 2 and 3). Since the EDX spectrometry measurements are acquired at micrometer depths whereas XPS data are obtained from the surface layer of nanometer thickness $[15,16]$, the experimental results suggest that the core of the particle is essentially $\gamma-\mathrm{Fe}_{2} \mathrm{O}_{3}$ and the coating layers are $\mathrm{Zn}$ and $\mathrm{Cl}$ based.

XRD results show the presence of $\mathrm{ZnFe}_{2} \mathrm{O}_{4}$ and $\mathrm{Zn}(\mathrm{OH})_{2}$ phases in addition to the $\gamma-\mathrm{Fe}_{2} \mathrm{O}_{3}$ phase, but no clear $\mathrm{FeCl}_{3}$ crystal phase. These results therefore suggest that the layer of adsorbed $\mathrm{FeCl}_{3}$ was very thin and amorphous. Therefore, 

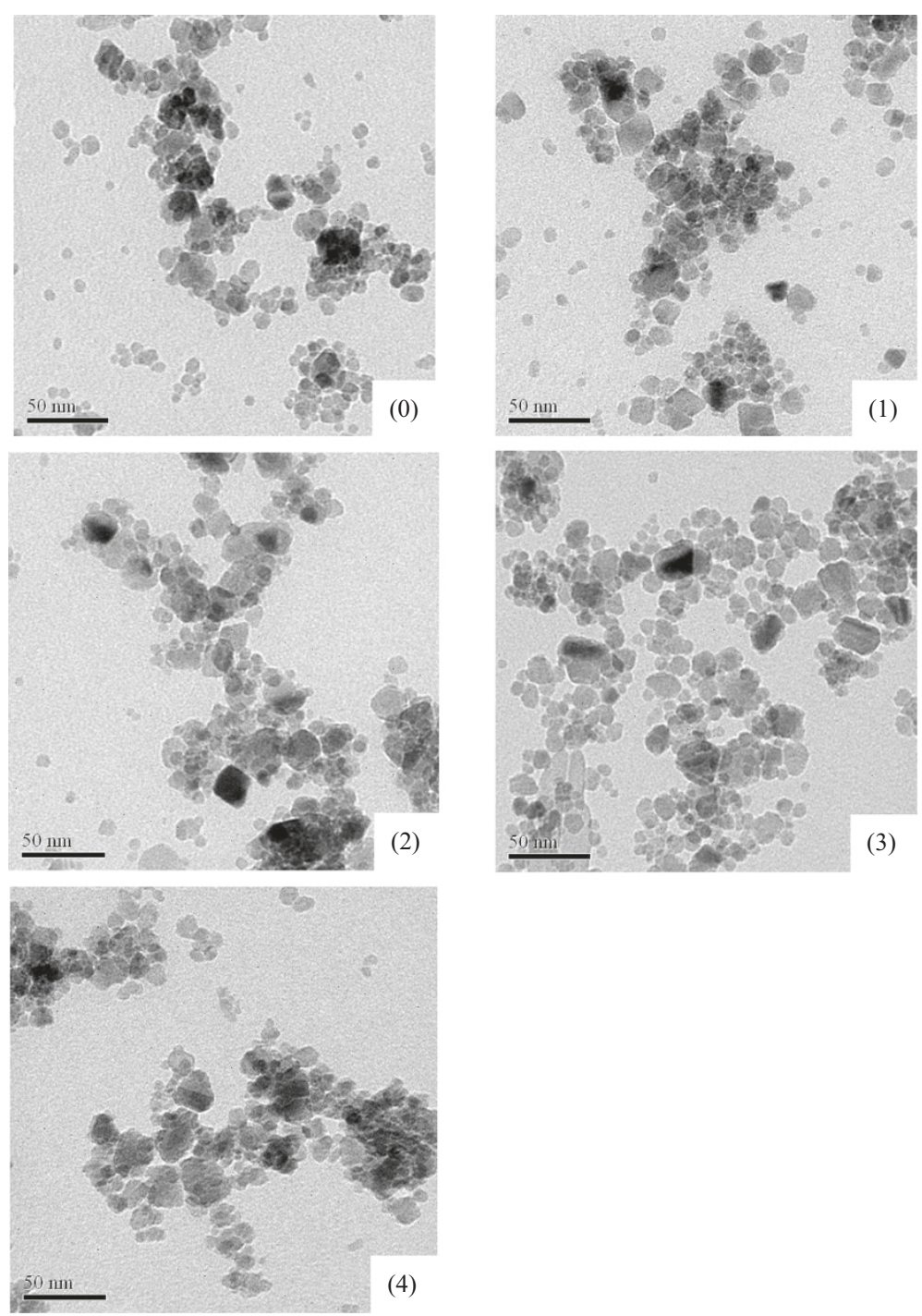

3)

Figure 1 Typical TEM images of the samples prepared without $\mathrm{NaOH}(0)$ and with increasing $\mathrm{NaOH}$ concentrations: 0.35 (1), 0.70 (2), 1.40 (3) and 2.10 M (4).

the structure of the composite nanoparticles consisted of four parts, namely, a $\gamma$ - $\mathrm{Fe}_{2} \mathrm{O}_{3}$ core, external shells of $\mathrm{ZnFe}_{2} \mathrm{O}_{4}$ and $\mathrm{Zn}(\mathrm{OH})_{2}$, and an outermost layer of adsorbed $\mathrm{FeCl}_{3}$. A schematic model of this structure is shown in Figure 5. Accordingly, the formation of the composite nanoparticles can be described as follows.

When the $\mathrm{FeOOH} / \mathrm{Mg}(\mathrm{OH})_{2}$ precursor was thermally treated with $\mathrm{FeCl}_{2}$ solution, $\mathrm{Mg}(\mathrm{OH})_{2}$ was dissolved, an amorphous $\mathrm{FeOOH}$ species was transformed into $\gamma$ - $\mathrm{Fe}_{2} \mathrm{O}_{3}$ crystallites, and $\mathrm{Fe}^{2+}$ was oxidized to $\mathrm{Fe}^{3+}$. While adding $\mathrm{ZnCl}_{2}$ to the solution, a precipitation reaction took place on the $\gamma-\mathrm{Fe}_{2} \mathrm{O}_{3}$ crystallites, which can be described as follows:

$$
\begin{aligned}
x\left[\mathrm{Fe}^{3+}\right. & \left.+3 \mathrm{OH}^{-}\right] \\
+y\left[\mathrm{Zn}^{2+}+2 \mathrm{OH}^{-}\right] & \rightarrow\left[\mathrm{Fe}(\mathrm{OH})_{3}\right]_{x}\left[\mathrm{Zn}(\mathrm{OH})_{2}\right]_{y}
\end{aligned}
$$

If $y / x>1 / 2$, then

$$
\begin{aligned}
{\left[\mathrm{Fe}(\mathrm{OH})_{3}\right]_{x}\left[\mathrm{Zn}(\mathrm{OH})_{2}\right]_{y} \rightarrow } & {\left[\mathrm{ZnFe} e_{2} \mathrm{O}_{4}\right]_{x / 2}\left[\mathrm{Zn}(\mathrm{OH})_{2}\right]_{y-x / 2} } \\
& +2 x \mathrm{H}_{2} \mathrm{O}
\end{aligned}
$$

Thus, $\mathrm{ZnFe}_{2} \mathrm{O}_{4}$ grew epitaxially on the $\gamma-\mathrm{Fe}_{2} \mathrm{O}_{3}$ crystallites and some $\mathrm{Zn}(\mathrm{OH})_{2}$ outside of the $\mathrm{ZnFe}_{2} \mathrm{O}_{4}$ layer was preserved. Clearly, additional $\mathrm{NaOH}$ enhanced the reaction so that $x$ and $y$ increased with increasing $\mathrm{NaOH}$ content. In addition, $\mathrm{Fe}^{3+}$ and $\mathrm{Cl}^{-}$in the liquid phase were adsorbed and were subsequently converted to composite nanoparticles coated with $\mathrm{FeCl}_{3}$. Experimental results show that with increasing $\mathrm{NaOH}$ content, the amount of phases based on $\mathrm{Zn}$ increased. When the $\mathrm{NaOH}$ concentration was lower than $0.70 \mathrm{M}$, the $\mathrm{FeCl}_{3}$ phase was nearly unchanged since the $\mathrm{Fe}: \mathrm{Cl}$ ratio is almost invariant (Table 2); thus, only when the $\mathrm{NaOH}$ 
concentration exceeded $0.70 \mathrm{M}$ did the amount of $\mathrm{FeCl}_{3}$ increase clearly with $\mathrm{NaOH}$ concentration due to increasing amount of $\mathrm{Cl}$. This means that the value of $x$ in equation (2) increased with $\mathrm{NaOH}$ concentration at low $\mathrm{NaOH}$ concentrations, i.e., the amount of $\mathrm{ZnFe}_{2} \mathrm{O}_{4}$ phase increased clearly with $\mathrm{NaOH}$ concentration when the $\mathrm{NaOH}$ concentration did not exceed $0.70 \mathrm{M}$, but it increased slightly with $\mathrm{NaOH}$ concentration when the $\mathrm{NaOH}$ concentration was $>0.70 \mathrm{M}$. As the results in Table 2 show a consistent increase of the $\mathrm{Zn}$ : Fe ratio with increasing $\mathrm{NaOH}$ concentration, it can be judged that $\mathrm{Zn}(\mathrm{OH})_{2}$ increased slightly under low $\mathrm{NaOH}$ concentration $(<0.70 \mathrm{M})$ and did clearly under high $\mathrm{NaOH}$ consentration $(>0.70 \mathrm{M})$. According to the relation between the specific magnetization and $\mathrm{NaOH}$ content, the action of additional $\mathrm{NaOH}$ can be discussed further as follows.

The magnetization exhibited stepwise distribution, being strongest in the innermost region of the composite nanoparticle: $\mathrm{Zn}(\mathrm{OH})_{2} / \mathrm{FeCl}_{3}<\mathrm{ZnFe}_{2} \mathrm{O}_{4}<\gamma-\mathrm{Fe}_{2} \mathrm{O}_{3}$. The specific magnetization of the composite nanoparticle system $\sigma$ can be described as follows:

$$
\begin{aligned}
\sigma= & \phi_{\gamma-F e} \sigma_{\gamma-F e}+\phi_{Z n-F e} \sigma_{Z n-F e}+\phi_{Z n} \sigma_{Z n} \\
& +\phi_{C l} \sigma_{C l}
\end{aligned}
$$

where $\phi_{\gamma-\mathrm{Fe}}, \phi_{\mathrm{Zn}-\mathrm{Fe}}, \phi_{\mathrm{Zn}}$, and $\phi_{\mathrm{Cl}}$ are mass fractions; $\sigma_{\gamma^{-}}$ Fe, $\sigma_{\mathrm{Zn}-\mathrm{Fe}}, \sigma_{\mathrm{Zn}}$, and $\sigma_{\mathrm{Cl}}$ are the specific magnetizations for the $\gamma-\mathrm{Fe}_{2} \mathrm{O}_{3}, \mathrm{ZnFe}_{2} \mathrm{O}_{4}, \mathrm{Zn}(\mathrm{OH})_{2}$, and $\mathrm{FeCl}_{3}$ phases, respectively. $\sigma_{\gamma-\mathrm{Fe}}>\sigma_{\mathrm{Zn}-\mathrm{Fe}}>\sigma_{\mathrm{Zn}}\left(\approx \sigma_{\mathrm{Cl}}\right)$ since nanoscale $\mathrm{ZnFe}_{2} \mathrm{O}_{4}$ could be weakly ferromagnetic [17], and $\mathrm{Zn}(\mathrm{OH})_{2}$ and $\mathrm{FeCl}_{3}$ are paramagnetic. Considering as

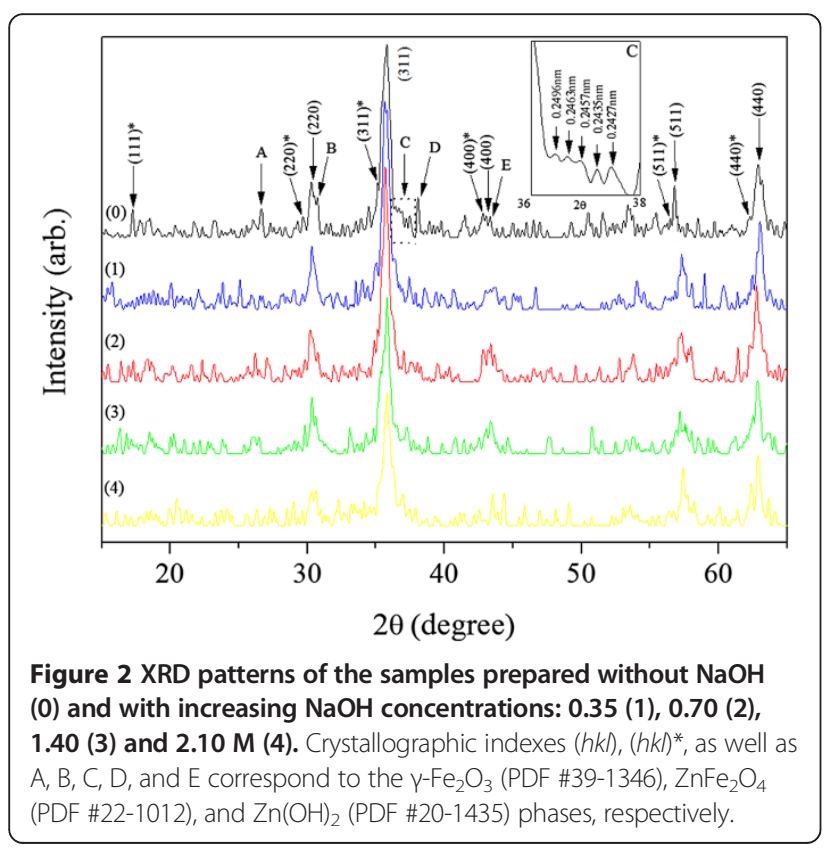

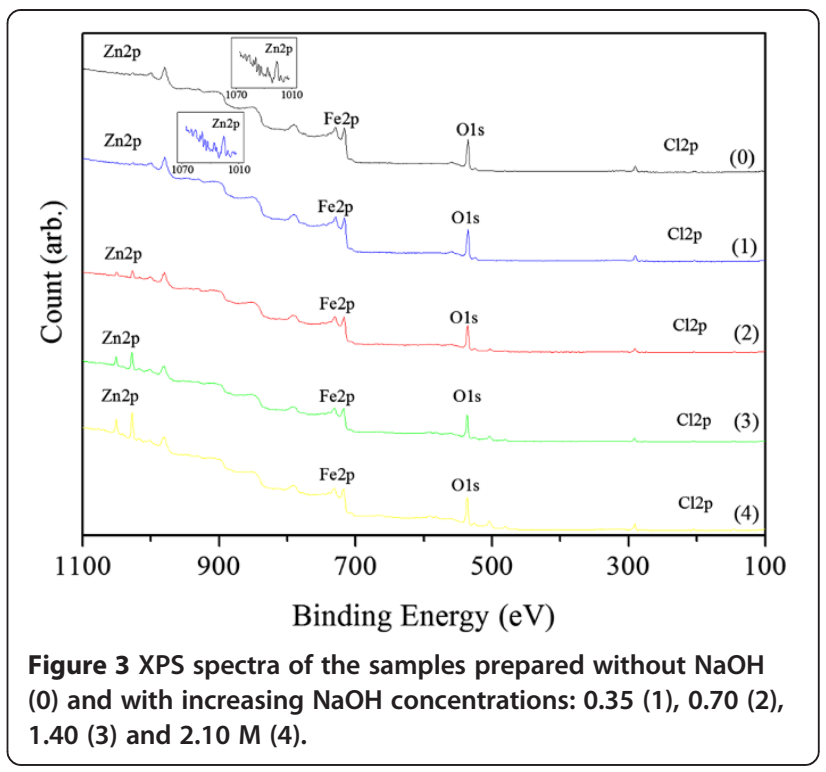

well that $\phi_{Y-\mathrm{Fe}}+\phi_{\mathrm{Zn}-\mathrm{Fe}}+\phi_{\mathrm{Zn}}+\phi_{\mathrm{Cl}}=1$, equation (4) can be written as

$$
\sigma=\sigma_{\gamma-F e}-\phi_{Z n-F e}\left(\sigma_{\gamma-F e}-\sigma_{Z n-F e}\right)-\phi_{Z n}\left(\sigma_{\gamma-F e}-\sigma_{Z n}\right)-\phi_{C l}\left(\sigma_{\gamma-F e}-\sigma_{C l}\right)
$$

Qualitatively, the variation of the specific magnetization $\Delta \sigma$ can be described as follows:

$$
\begin{aligned}
\Delta \sigma= & -\Delta \phi_{Z n-F e}\left(\sigma_{\gamma-F e}-\sigma_{Z n-F e}\right)-\Delta \phi_{Z n}\left(\sigma_{\gamma-F e}-\sigma_{Z n}\right) \\
& -\Delta \phi_{C l}\left(\sigma_{\gamma-F e}-\sigma_{C l}\right)
\end{aligned}
$$

The mass fraction of every phase should be directly

\begin{tabular}{|c|c|c|c|c|}
\hline & $01 \mathrm{~s}$ & $\mathrm{Fe} 2 p_{3 / 2}$ & $\mathrm{Zn} 2 \mathrm{p}_{3 / 2}$ & $\mathrm{Cl} 2 \mathrm{p}$ \\
\hline 0 & 529.90 & 710.44 & 1021.15 & 198.07 \\
\hline 1 & 529.94 & 710.71 & 1021.40 & 198.19 \\
\hline 2 & 529.93 & 710.88 & 1021.17 & 198.10 \\
\hline 3 & 529.84 & 710.79 & 1021.16 & 198.13 \\
\hline 4 & 530.08 & 710.98 & 1021.20 & 198.28 \\
\hline $\mathrm{Fe}_{2} \mathrm{O}_{3}^{(\mathrm{a})}$ & 530.00 & 710.70 & & \\
\hline $\mathrm{ZnFe}_{2} \mathrm{O}_{4}^{(\mathrm{b})}$ & 530.84 & 710.95 & 1020.86 & \\
\hline $\mathrm{Zn}(\mathrm{OH})_{2}^{(\mathrm{c})}$ & 531.35 & & 1022.30 & \\
\hline $\mathrm{FeCl}_{3}^{(\mathrm{a})}$ & & 711.10 & & 198.70 \\
\hline $\mathrm{ZnCl}_{2}^{(\mathrm{d})}$ & & & 1022.50 & 199.85 \\
\hline
\end{tabular}
proportional to the molar ratio. The mass fraction is

Table 1 Binding energy data from XPS (eV) for samples prepared without $\mathrm{NaOH}(0)$ and with increasing $\mathrm{NaOH}$ concentrations: 0.35 (1), $0.70(2), 1.40$ (3) and $2.10 \mathrm{M}$ (4)

Note: ${ }^{(a)}$ The data are taken from the Hand book of X-ray photoelectron.

${ }^{(b)}$ The data are taken from Ref. [17].

(c)The data are taken from Appl. Sur. Sci. 1982, 10: 523, T. L. Barr, J. J. Hackenberg.

${ }^{(d)}$ The data are taken from Ref. [13]. 
Table 2 Atomic percentages of $\mathrm{O}, \mathrm{Fe}, \mathrm{Cl}$, and $\mathrm{Zn}$ from XPS measurements for samples prepared without $\mathrm{NaOH}(0)$ and with increasing $\mathrm{NaOH}$ concentrations: 0.35 (1), 0.70 (2), 1.40 (3) and 2.10 M (4)

\begin{tabular}{ccccccc}
\hline & $\mathbf{O}$ & Fe & Zn & Cl & Fe:Zn:Cl & Cl:Zn \\
\hline 0 & 71.43 & 25.16 & 0.61 & 2.80 & $1: 0.024: 0.111$ & $1: 0.22$ \\
1 & 72.36 & 23.69 & 1.36 & 2.59 & $1: 0.057: 0.109$ & $1: 0.52$ \\
2 & 69.60 & 25.05 & 2.65 & 2.70 & $1: 0.108: 0.106$ & $1: 1.02$ \\
3 & 68.01 & 22.89 & 5.91 & 3.19 & $1: 0.258: 0.139$ & $1: 1.86$ \\
4 & 68.06 & 20.90 & 7.82 & 3.22 & $1: 0.374: 0.154$ & $1: 2.43$ \\
\hline
\end{tabular}

defined as $\phi_{i}=m_{i} / \sum m_{i}$, where $m_{\mathrm{i}}$ represents $m_{\gamma \text {-Fe }}, m_{\mathrm{Zn}-\mathrm{Fe}}$, $m_{\mathrm{Zn}}$, and $m_{\mathrm{Cl}}$, which are the masses of $\gamma-\mathrm{Fe}_{2} \mathrm{O}_{3}, \mathrm{ZnFe}_{2} \mathrm{O}_{4}$, $\mathrm{Zn}(\mathrm{OH})_{2}$, and $\mathrm{FeCl}_{3}$ phases in the sample, respectively. In the modification to this equation, the mass of the $\gamma-\mathrm{Fe}_{2} \mathrm{O}_{3}$ phase $m_{\gamma-\mathrm{Fe}}$ may be treated as constant. Thus, when $m_{\mathrm{Cl}}$ was nearly constant under low amounts of additional $0.70 \mathrm{M} \mathrm{NaOH}, \phi_{\mathrm{Cl}}$ decreased as $m_{\mathrm{Zn}-\mathrm{Fe}}$ and $m_{\mathrm{Zn}}$ increased. As a consequence, when $\sum m_{i}$ increased at low amounts of $\mathrm{NaOH}, \Delta \phi_{\mathrm{Cl}}$ was negative since $m_{\mathrm{Cl}}$ was unchanged, i.e., $-\Delta \phi_{\mathrm{Cl}}>0$; thus, equation (6) can be written as

$$
\begin{aligned}
\Delta \sigma= & -\Delta \phi_{Z n-F e}\left(\sigma_{\gamma-F e}-\sigma_{Z n-F e}\right)-\Delta \phi_{Z n}\left(\sigma_{\gamma-F e}-\sigma_{Z n}\right) \\
& +\left|\Delta \phi_{C l}\right|\left(\sigma_{\gamma-F e}-\sigma_{C l}\right)
\end{aligned}
$$

Equation (7) shows that increment of the mass fraction of the $\mathrm{ZnFe}_{2} \mathrm{O}_{4}$ and $\mathrm{Zn}(\mathrm{OH})_{2}$ phases lowered the value of $\sigma$, whereas a decrement in the mass fraction of the $\mathrm{FeCl}_{3}$ phase increased it. For sample (1), $x$ and $y$ in the precipitation reaction described by equation (2) increased slightly compared with those for sample (0); hence, $\Delta \phi_{\mathrm{Zn}-\mathrm{Fe}}, \Delta \phi_{\mathrm{Zn}}$, and $\Delta \phi_{\mathrm{Cl}}$ were very small compared with their counterparts for sample (0). Therefore, $\sigma$ of sample (1) was about the same as that of sample (0). For sample (2), $x$ and $y$ in the precipitation reaction increased, but the increment of $x$ could be larger than $y$. Thus, it can be judged from equation (3) that the increment in molar content $x / 2$ of the $\mathrm{ZnFe}_{2} \mathrm{O}_{4}$ phase would be larger than that of the $\mathrm{Zn}(\mathrm{OH})_{2}$ phase $(y-x / 2)$, i.e., $\Delta \phi_{\mathrm{Zn}-\mathrm{Fe}}>\Delta \phi_{\mathrm{Zn} \text {. }}$. Since $\sigma_{\gamma-\mathrm{Fe}}-\sigma_{\mathrm{Zn}-\mathrm{Fe}}<\sigma_{\gamma-\mathrm{Fe}}-\sigma_{\mathrm{Zn}}\left(\approx \sigma_{\gamma-\mathrm{Fe}}-\sigma_{\mathrm{Cl}}\right)$ and $\left|\Delta \phi_{\mathrm{Cl}}\right|$ is

Table 3 Atomic percentages of $\mathrm{O}, \mathrm{Fe}, \mathrm{Cl}$, and $\mathrm{Zn}$ from EDX spectrometry measurements for samples prepared without $\mathrm{NaOH}(0)$ and with increasing $\mathrm{NaOH}$ concentrations: 0.35 (1), 0.70 (2), 1.40 (3) and $2.10 \mathrm{M}$ (4)

\begin{tabular}{ccccccc}
\hline & $\mathbf{O}$ & Fe & Zn & Cl & Fe:Zn:Cl & Cl:Zn \\
\hline 0 & 55.75 & 42.15 & 0.48 & 1.62 & $1: 0.011: 0.038$ & $1: 0.29$ \\
1 & 57.85 & 39.97 & 0.60 & 1.58 & $1: 0.015: 0.040$ & $1: 0.38$ \\
2 & 55.41 & 41.36 & 1.70 & 1.53 & $1: 0.041: 0.037$ & $1: 1.11$ \\
3 & 55.57 & 39.63 & 3.15 & 1.65 & $1: 0.079: 0.042$ & $1: 1.88$ \\
4 & 53.56 & 39.51 & 4.86 & 2.07 & $1: 0.123: 0.053$ & $1: 2.32$ \\
\hline
\end{tabular}

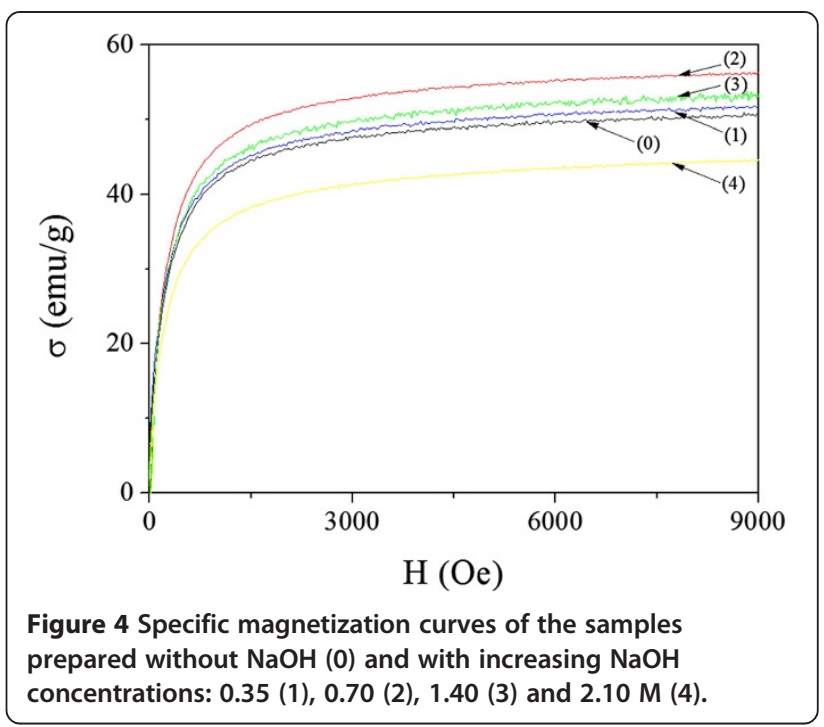

proportional to $\Delta \phi_{\gamma-\mathrm{Fe}}+\Delta \phi_{\mathrm{Zn}},\left|\Delta \phi_{\mathrm{Cl}}\right|\left(\sigma_{\gamma-\mathrm{Fe}}-\sigma_{\mathrm{Cl}}\right)>\Delta \phi_{\mathrm{Zn}-}$ $\mathrm{Fe}\left(\sigma_{\gamma-\mathrm{Fe}}-\sigma_{\mathrm{Zn}-\mathrm{Fe}}\right)+\Delta \phi_{\mathrm{Zn}}\left(\sigma_{\gamma-\mathrm{Fe}}-\sigma_{\mathrm{Zn}}\right)$. Consequently, the $\sigma$ value of sample (2) was greater than those for samples (0) and (1).

When the concentration of additional $\mathrm{NaOH}$ exceeded $0.70 \mathrm{M}$, the amount of $\mathrm{FeCl}_{3}$ phase increased with the $\mathrm{NaOH}$ content. Therefore, the variation of $\sigma$ should be described as follows:

$$
\begin{aligned}
\Delta \sigma= & -\Delta \phi_{Z n-F e}\left(\sigma_{\gamma-F e}-\sigma_{Z n-F e}\right)-\Delta \phi_{Z n}\left(\sigma_{\gamma-F e}-\sigma_{Z n}\right) \\
& -\Delta \phi_{C l}\left(\sigma_{\gamma-F e}-\sigma_{C l}\right)
\end{aligned}
$$

Therefore, the $\sigma$ weakened in the order of samples (2) to (4).

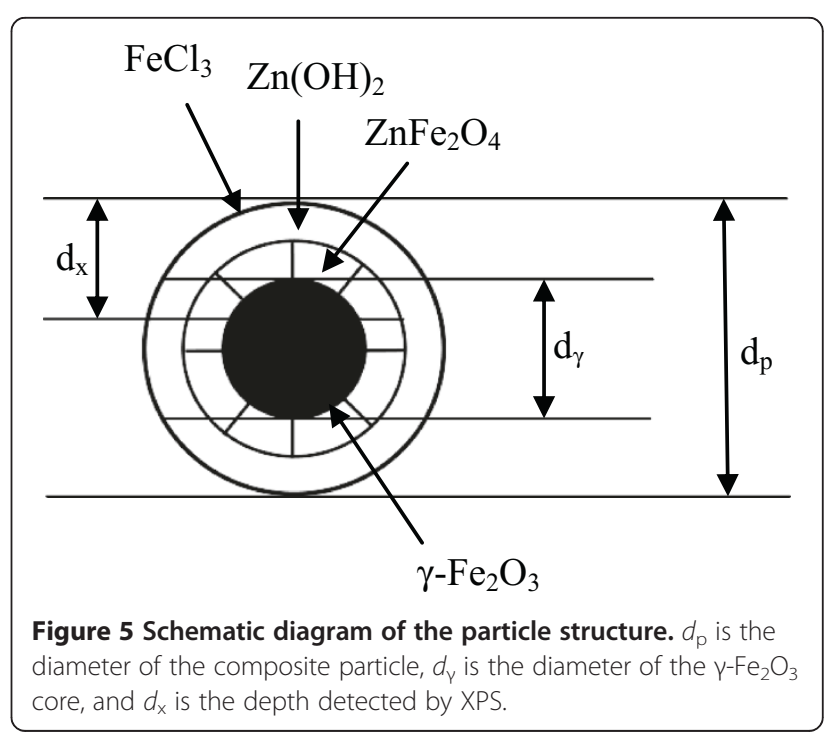




\section{Conclusions}

During liquid-phase synthesis of $\gamma-\mathrm{Fe}_{2} \mathrm{O}_{3}$ nanoparticles from precursor composed of amorphous $\mathrm{FeOOH}$ and $\mathrm{Mg}(\mathrm{OH})_{2}$ by chemically induced transition in $\mathrm{FeCl}_{2}$ solution, $\mathrm{Mg}(\mathrm{OH})_{2}$ dissolved, FeOOH transformed into $\gamma-\mathrm{Fe}_{2} \mathrm{O}_{3}$ nanocrystallites, and $\mathrm{Fe}^{2+}$ was oxidized partially into $\mathrm{Fe}^{3+}$. The surface of the particles could be modified by adding $\mathrm{ZnCl}_{2}$ to form $\gamma-\mathrm{Fe}_{2} \mathrm{O}_{3} / \mathrm{ZnFe}_{2} \mathrm{O}_{4}$ composite nanoparticles coated with $\mathrm{Zn}(\mathrm{OH})_{2}$ and adsorbed $\mathrm{FeCl}_{3}$. Such composite nanoparticles exhibited stepwise distribution of magnetization from inner to outer regions. Thus, they could be easily dispersed in carrier liquid to form excellent ferrofluids [18]. Experimental results indicate that when the amount of $\mathrm{ZnCl}_{2}$ solution was constant $(1 \mathrm{M}, 50 \mathrm{~mL})$, the modification could be enhanced by addition of $\mathrm{NaOH}$. When the concentration of additional $\mathrm{NaOH}$ was below $0.70 \mathrm{M}$, the amount of $\mathrm{FeCl}_{3}$ adsorbed was unchanged, but that of $\mathrm{ZnFe}_{2} \mathrm{O}_{4}$ and $\mathrm{Zn}(\mathrm{OH})_{2}$ increased slightly, increasing the magnetization of the products. When the concentration of additional $\mathrm{NaOH}$ exceeded $0.70 \mathrm{M}$, the amount of adsorbed $\mathrm{FeCl}_{3}$ and $\mathrm{ZnFe}_{2} \mathrm{O}_{4}$ and $\mathrm{Zn}(\mathrm{OH})_{2}$ phases increased, and the specific magnetization of the as-prepared products weakened with increasing amount of $\mathrm{NaOH}$. These results show that surface modification during synthesis of the composite nanoparticles $\gamma-\mathrm{Fe}_{2} \mathrm{O}_{3} / \mathrm{ZnFe}_{2} \mathrm{O}_{4}$ coated with $\mathrm{Zn}(\mathrm{OH})_{2}$ and $\mathrm{FeCl}_{3}$ could be enhanced by additional $\mathrm{NaOH}$ to obtain various proportions of phases in the composite particles. This route could be an interesting route for preparing magnetic composite nanoparticles with novel properties. It could potentially be used to prepare other composite nanoparticles based on $\gamma-\mathrm{Fe}_{2} \mathrm{O}_{3}$. In this regard, it will be investigated further.

\section{Competing interests}

The authors declare that they have no competing interests.

\section{Authors' contributions}

LC carried out characteristical studies of the nanoparticles, participated in the sequence alignment and drafted the manuscript. JL conceived of the study, and participated in its design and coordination and help to draft the manuscript. YL carried out the preparation of samples. XL carried out the measurements of both VSM and XRD. JL carried out the analysis of both EDX and XPS results. XG performed the analysis of TEM results. DL participated in the design of the study. All authors read and approval the final manuscript.

\section{References}

1. Willard MA, Kurihara LK, Carpenter EE, Calvin S, Harris VG: Chemically prepared magnetic nanoparticles. Int Mater Rev 2004, 49:125-170.

2. Murray $C B$, Kagan $C R$, Bawendi MG: Synthesis and characterization of monodisperse nanocrystals and close-packed nanocrystal assemblies. Annu Rev Mater 2000, 30:545-610.

3. Szabó DV, Vollath D: Nanocomposites from coated nanoparticles. Adv Mater 1999, 11:1313-1316.

4. Reddy LH, Arias JL, Nicolas J, Couvreur P: Magnetic nanoparticles: design and characterization, toxicity and biocompatibility, pharmaceutical and biomedical applications. Chem Rev 2012, 112:5818-5878.

5. Sun SH: Recent advances in chemical synthesis, self-assembly, and applications of FePt nanoparticles. Adv Mater 2006, 18:393-403.

6. Nogués J, Sort J, Langlais V, Skumryev V, Suriñach S, Muñoz JS, Baró MD: Exchange bias in nanostructures. Phys Rep 2005, 422:65-117.

7. Cushing BL, Kolesnichenko VL, O'Connor CJ: Recent advances in the liquid-phase syntheses of inorganic nanoparticles. Chem Rev 2004, 104:3893-3946.

8. Zhang QM, Li J, Lin YQ, Liu XD, Miao H: The preparation and characterization of Ni-Fe bioxide composite nanoparticles. J Alloy Compd 2010, 508:396-399

9. Miao H, Li J, Lin Y, Liu X, Zhang Q, Fu J: Characterization of $\mathrm{Y}-\mathrm{Fe}_{2} \mathrm{O}_{3}$ nanoparticles prepared by transformation of a-FeOOH. Chin Sci Bull 2011, 56:2383-2388

10. Wen BC, Li J, Lin YQ, Liu XD, Fu J, Miao H, Zhang QM: A novel preparation method for $\mathrm{\gamma}-\mathrm{Fe}_{2} \mathrm{O}_{3}$ nanoparticles and their characterization. Mater Chem Phys 2011, 128:35-38.

11. Chen LL, Li J, Lin YQ, Liu XD, Lin LH, Li DC: Surface modification and

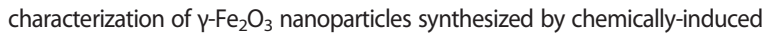
transition. Mater Chem Phys 2013, 141:828-834.

12. Narayanaswamy A, Xu HF, Pradhan N, Peng XG: Crystalline nanoflowers with different chemical compositions and physical properties grown by limited ligand protection. Angew Chem Int Ed 2006, 45:5361-5364.

13. Seals $R$, Alexander R, Taylor LT, Dillard JG: Core electron binding energy study of group Ilb-VIla compounds. Inorg Chem 1973, 12:2485-2487.

14. Arulmurugan R, Vaidyanathan G, Sendhilnathan S, Jeyadevan B: Co-Zn ferrite nanoparticles for ferrofluid preparation: Study on magnetic properties. Physica B 2005, 363:225-231.

15. Tanuma S, Powell CJ, Penn DR: Calculations of Electron Inelastic Mean Free Paths III. Data for 15 Inorganic Compounds over the $50-2000 \mathrm{eV}$ Range. Surf Interface Anal 1991, 17:927-939.

16. Srnová-Šloufová I, Vlčková B, Bastl Z, Hasslett TL: Bimetallic (Ag)Au nanoparticles prepared by the seed growth method: Two-dimensional assembling, characterization by energy dispersive X-ray analysis, X-ray photoelectron spectroscopy, and surface enhanced Raman spectroscopy, and proposed mechanism of growth. Langmuir 2004, 20:3407-3415.

17. Li J, Wang AR, Lin YQ, Liu XD, Fu J, Lin LH: A study of $\mathrm{ZnFe}_{2} \mathrm{O}_{4}$ nanoparticles modified by ferric nitrate. J Magn Magn Mater 2013, 330:96-100

18. Lin LH, Li J, Fu J, Lin YQ, Liu XD: Preparation, magnetization, and microstructure of ionic ferrofluids based on $\gamma-\mathrm{Fe}_{2} \mathrm{O}_{3} / \mathrm{Ni}_{2} \mathrm{O}_{3}$ composite nanoparticles. Mater Chem Phys 2012, 134:407-411.

doi:10.1186/1752-153X-8-40

Cite this article as: Chen et al:: Preparation of $\gamma-\mathrm{Fe}_{2} \mathrm{O}_{3} / \mathrm{ZnFe}_{2} \mathrm{O}_{4}$ nanoparticles by enhancement of surface modification with $\mathrm{NaOH}$. Chemistry Central Journal 2014 8:40.

\section{Acknowledgments}

Financial support for this work was provided by the National Science Foundation of P.R. China (No. 51375039 and 11074205).

\section{Author details}

'School of Physical Science \& Technology, Southwest University, Chongqing 400715, People's Republic of China. ${ }^{2}$ School of Mechanical \& Control Engineering, Beijing Jiaotong University, Beijing 100044, People's Republic of China.

Received: 11 March 2014 Accepted: 16 June 2014

Published: 24 June 2014 